\title{
Estimating Shadow Economy and Tax Evasion: Evidence from Morocco
}

\author{
Nora Angour ${ }^{1} \&$ Mohammed Nmili ${ }^{1}$ \\ ${ }^{1}$ Research Laboratory in Management, Finance and Social Economy (LAREMFES), Faculty of Economic and \\ Social Sciences, Sidi Mohamed Ben Abdellah University, Fez, Morocco \\ Correspondence: Nora Angour, Laboratoire de Recherche en Managment, Finance et Economie Scoiale \\ (LAREMFES), faculté des sciences juridiques, économiques et sociales Fès, BP 42 A, Fès, Maroc, Morocco. Tel: \\ 212-661-353-861. E-mail: noraangour17@gmail.com
}

Received: February 17, 2019

Accepted: April 1, 2019

Online Published: April 7, 2019

doi:10.5539/ijef.v11n5p7

URL: https://doi.org/10.5539/ijef.v11n5p7

\begin{abstract}
The purpose of this article is to assess the extent of tax evasion in Morocco for the period from 1985 to 2016. Aware of the difficulty of directly measuring a phenomenon that is hidden by nature, we are opting to use an indirect approach commonly applied in the empirical literature. Hence, we use the MIMIC method, which makes it possible first to estimate the shadow sector economy, and then deduct the tax evasion from it. Our results showed that the average extent of tax evasion and shadow economy in Morocco achieve $6.19 \%$ and $38.74 \%$ of GDP during the period studied from 1985 to 2016. Also, the tax burden, the rate of openness, the rate of urbanization, the agricultural sector, and unemployment rate are the main determinants of tax evasion in Morocco.
\end{abstract}

Keywords: tax evasion, shadow economy, MIMIC approach, Morocco

\section{Introduction}

Since the 2008 financial crisis, the sustainability of public finances has been weakened and called into question by excessive debt and swelling corporate deficits. Thus, to face this situation, and in order to increase tax revenues, several States have embarked on a struggle against tax evasion and tax avoidance. This struggle has become an alternative and a global priority, as the majority of countries have strengthened measures to combat tax evasion, which has marked an unprecedented historical acceleration. Undeniably, effectively combating this scourge requires first of all to know it and to understand the factors influencing the taxpayer's decision in tax matters, and then to quantify it in order to know its magnitude and its range in public finances. The problem of evaluating quantitatively tax evasion was being studied considerably for many countries. Thus, various estimation methods have been proposed. These methods can be classified into two approaches: direct and indirect.

On one hand, direct approach methods directly measure the problem of tax evasion, based on individual information disclosed, either voluntarily from household surveys (O'Higgins, 1980), mandatorily through tax audits (IRS, 1963), or deduced from tax amnesties (Richupan, 1984).

On the other hand, the indirect methods use an observable indicator, from which an estimate of tax evasion is inferred through the measurement of the shadow sector economy in general: the national accounts approach (McAfee, 1980), the monetary approach (Gutmann, 1977; Feige, 1979; Tanzi, 1980), the labor market participation rate approach, the physical inputs approach (Kaufmann \& Kaliberda, 1996; Lacko, 1996), and the MIMIC approach "Multiple Indicators, Multiple Causes" (Frey \& Weck-Hanneman, 1984).

In the Moroccan case, several studies have been carried out on tax evasion, including qualitative analysis of the phenomenon, its causes, consequences and legal aspects. However, few studies have been conducted to quantify tax evasion due to the absence of official statistics. These studies remain very limited and focus on assessments either on a single tax and/or on a specific year (Essoulahi \& Abbadi, 1980; Naïmi, 1982; ...etc.). For example, Bouchareb (2005) reports that tax evasion in 2002 is estimated at 12 billion Dirhams.

In this paper, we use the MIMIC latent variable approach to estimate the annual sizes of the shadow economy and tax evasion in Morocco for the period 1985-2016. 
In the following of this paper, we will first describe the MIMIC method. Then, we will detail the application of this method to the Moroccan economy by specifying the different variables used and their sources. Finally, we will present and analyze the obtained results.

\section{Methodology}

\subsection{MIMIC Description}

The MIMIC (Multiple Indicators Multiple Causes) structural model is a specific case of the SEM structural equation models that allows to specify statistical relationships between cause variables (observed variables) and latent variables (not observed) which, in turn, indirectly affect a set of observed indicators. This model has been used by Zellner, Arnold (1970), Goldberger (1972) for other studies not dealing with the evaluation of the shadow economy or tax evasion. Generally, MIMIC models consist of two parts: the measurement model (measurement equations) and the structural model (structural equations). The measurement equations link the unobserved variables with the indicators (which are observed). While the structural equations specify the relationships between the latent variables and their causes (assumed observed).

Based on data from the different observed variables (causes and indicators), a specific model is constructed to determine the unobserved variable. Its scheme is described as follows:

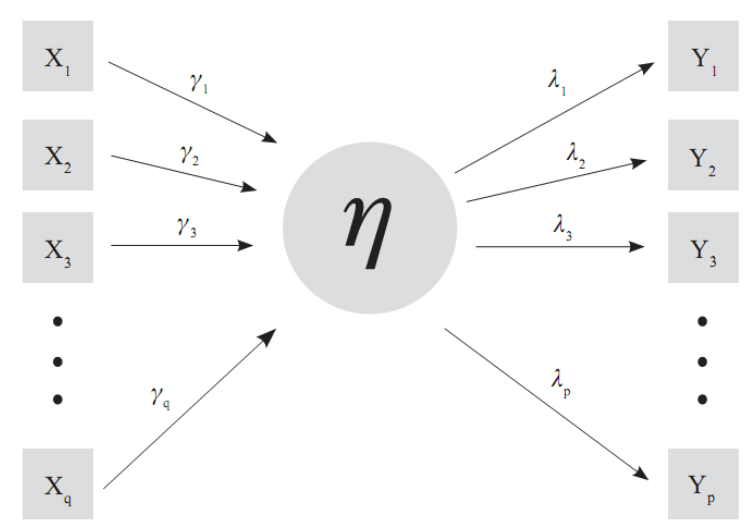

Figure 1. Structure of a MIMIC model q-1-p (Giles \& Tedds, 2002)

In this diagram, the unobserved variable $\eta$ is related to $q$ observable variables that may be potential causes $x=\left[x_{1}, x_{2}, \ldots, x_{q}\right]$. This introduces a first time-series equation of the system:

$$
\eta_{t}=\gamma^{\prime} x_{t}+\xi_{t}
$$

With $\gamma^{\prime}$ a vector of q coefficients describing the relationship between $\eta_{t}$ et $x_{t}$, et $\xi_{t}$ an error term.

The above equation is called a structure model which is simply a regression model with an unobserved variable.

Since $\eta_{t}$ is not measurable, the idea is that it has an impact on other observable variables. These are called indicators and their relationship to $\eta_{t}$ is described with the so-called measurement model:

$$
y_{t}=\lambda \eta_{t}+\varepsilon_{t}
$$

With $y_{t}=\left[y_{1 t}, y_{2 t}, \ldots, y_{p t}\right]$ a vector of $\mathrm{p}$ indicators, $\lambda$ a vector of $\mathrm{p}$ coefficient describing the relationship between $y_{t}$ and $\eta_{t}$, and $\varepsilon_{t}$ an error term. It is assumed in this model that the two error terms are uncorrelated to each other and have zero means (centered variables).

By connecting the two equations of the model through the unobserved variable, we obtain the following equation:

$$
y_{t}=\Pi x_{t}+v_{t}
$$

With: $\Pi=\lambda \gamma^{\prime}$ and $v_{t}=\lambda \xi_{t}+\varepsilon_{t}$. The problem thus appears as an equation of a linear regression. However, the resolution is performed under the constraint that the rank of the matrix $\Pi$ is unitary.

The MIMIC model thus formulated is unable to determine all parameters. So, Giles and Tedds (2002) introduced a convention that simplifies the resolution. They suggest to put the first element of $\lambda$ to 1 .

Finally, the estimation of the parameters in the MIMIC model is obtained using the covariance matrix of the 
model. This matrix describes the relationship between the observable variables in terms of their covariances and is given by:

$$
\Sigma=\left[\begin{array}{cc}
\Pi \Phi \gamma+\lambda \Psi+\Theta & \Pi \Phi \\
\Phi \Pi^{\prime} & \Phi
\end{array}\right]
$$

With $\Sigma$ the whole covariance matrix of the MIMIC model

$\Phi$ the covariance matrix of $x_{t}$

$\Psi$ the variance of $\xi_{t}$

$\Theta$ the covariance matrix of $\varepsilon_{t}$.

The parameters are estimated in such a way that $\Sigma$ is as close as possible to the covariance matrix of samples.

In the literature, several applications of the MIMIC method are made to estimate the size of shadow economy using different causes and indicators in different countries. The application of the MIMIC model to estimate the size and development of the shadow economy and thus tax evasion in the case of the Moroccan economy requires determining the variables to be used and collecting the necessary data.

\subsection{The Causes of the Shadow Economy}

There exists a several causes of the shadow economy raised in the theoretical and empirical literature, however we will simply study the causes considered in our empirical case.

Government employment: It measures the degree of economic freedom and government intervention in the economy. Hence, it is assumed that an increase in the level of regulation intensifies the shadow economy (e.g. Aigner et al., 1988; Dell'Anno et al., 2004; Johnson et al., 1998). This assumption is justified by the fact that labor market regulation, trade barriers, and restrictions on the employment of foreigners, lead to higher labor costs in the formal economy (Schneider, 2012). Therefore, this fact contributes to the concomitant expansion of the shadow economy and the rise in the unemployment rate (Schneider \& Enste, 2002).

Empirical studies introduce an index of economic freedom as a proxy for public employment. It is assumed, for instance, that a negative relationship links economic freedom and the shadow economy: a low index of economic freedom implies a significant share of the shadow economy in GDP. In fact, in countries with low economic freedom, the shadow economy exceeds $40 \%$ of GDP while in countries with a high freedom index; it is around 16\% (Eiras, 2003). In addition, other studies consider public spending as an approximation of the regulatory burden, and that high public spending will lead to an increase in the size of the public sector, thus reducing economic freedom (Hassan \& Schneider, 2016). This reasonably leads to the growth of the shadow economy. On the other hand, it is essential to clarify that the perception of the quality of public spending has an inverse impact where any increase in this quality would reduce tax evasion (Feld \& Schneider, 2010; Buehn \& Schneider, 2012).

Tax Burden: It exert a highly significant influence on the behaviour of economic agents in terms of tax regulation. It is therefore probably the most commonly used variable to explain the shadow economy and tax evasion, as confirmed by Dell'Anno (2003, p9): «in all the MIMIC applications this variable is included and, a strong direct effect on the shadow economy is confirmed».

In this sense, large empirical studies state a positive effect of the tax burden on the shadow economy, as well as tax evasion (Tanzi, 1999; Schneider \& Enste, 2000; Buehn, 2012). The tax burden can be divided into two separate types: the direct tax burden and the indirect tax burden (Schneider, 2005). It can be also introduced as a single variable including both the two types of tax. Otherwise, some studies use all mandatory taxes as a proportion of GDP, which include, in addition to the share of direct and indirect taxes, the share of social security contributions.

Unemployment rate: Its relationship with the shadow economy is ambiguous and cannot be easily predicted (Tanzi, 1999). On one hand, the higher the unemployment rate, the more people would seek to work in the shadow. On the other hand, the two formal and underground economies are linked and an increase in the unemployment rate indicates difficulties in the entire economy (Giles \& Tedds, 2002). Also, losses due to unemployment affect demand in both economies. Finally, there are people who work in both formal and informal jobs at the same time (Tanzi, 1999). Thus, the determination of the sign of this variable is not confirmed by economic theory, it can be positive or negative. The empirical analysis in each country could determinate the expected sign. For instance, Schneider et al. (2010) conclude that the unemployment rate has a positive impact on the shadow economy. Also, Alm and Yunus (2009) report in their study that tax evasion occurs more 
frequently when the unemployment rate increases. This result was similar to Williams and Schneider's study (2016).

In contrast, Buehn and Schneider (2008) in their study of the French case, found that unemployment has a negative long-term effect. The same result was confirmed by Boame (2009) who found a significant and negative relationship between the unemployment rate and tax evasion.

Inflation rate: It is the result of the imbalance observed between the money supply in circulation and the value of goods and services in the national economy. It therefore directly affects the purchasing power of households, which often use undeclared labour markets to meet their needs for goods and services. The effect of inflation on tax revenues has been well recognized in the theoretical literature since Tanzi's (1977) work. High inflation, in particular, between the due date and the tax collection date erodes the real value of tax revenues (Keynes-Oliveira-Tanzi effect, see Tanzi, 1978). Similarly, Fishburn (1981) notes that inflation has an impact on the decision to avoid taxes so that taxpayers in this situation seek to maintain their purchasing power. Thus, the inflation rate is positively correlated with the shadow economy and tax evasion (Crane \& Nourzad, 1986; Giles, 1999; Wang et al., 2006; Macias \& Cazzavillan, 2008).

Urbanization rate: The urbanization rate represents the share of the urban population in the total population. However, its relationship with the shadow economy remains undecided. Indeed, Tolger and Schneider (2007) have shown that the urbanization rate has a positive relationship with the shadow economy insofar as the concentration of the active population in urban areas have an incentive to engage in more underground activities. On the other hand, other studies show that the rate of urbanization corroborates negatively with the shadow economy. As such, the urbanization rate could be introduced as a proxy for representing the demand for public services in the urban area, as increased demand for public goods and services generates higher tax revenues (Davoodi \& Grigorian, 2007).

However, Elgin and Oyvat (2013) verified a relationship of the bell or the inverted U-shaped curve between the two variables. In this sense, the size of the informal economy increases in the early stages of urbanization then tends to decrease in the later stages of urbanization.

Importance of the agricultural sector: Several studies show the concentration of informal work in the agricultural sector (Stotsky and Wolde Mariam, 1997 for 43 sub-Saharan African countries; Angel-Urdinola and Tanabe, 2012 for countries in the Middle East and the North African region, including Morocco). In this context, Ghura (1998) states that the agricultural sector is difficult to tax owing to the prevalence of subsistence activities, which are largely informal.

In literature, the explanation for this concentration is that governments have weak control and reduced governance capacity in the agricultural sector and precisely in rural areas, creating perfect environments for underground activities. The agricultural sector is difficult to regulate due to the dispersion of populations and the low levels of income it generates, indicating a positive relationship between the importance of this sector and the underground economy (Vuletin, 2008; Torgler \& Schneider, 2007; Hassan \& Schneider, 2016).

Openness of the economy: Foreign trade transactions constitute an important tax base (Stostsky and Wolde Mariam, 1997). In this sense, it is difficult to transfer formal economic activity to the informal sector and hide transactions from the authorities (Medina \& Schneider, 2017), which means that trade openness is negatively associated with a large size of the shadow economy (Torgler \& Schneider, 2007).

In contrast, the opening of an economy to international trade probably encourages illegal activities of the shadow economy such as smuggling. In this case, the openness rate is positively correlated with the shadow economy. In this sense, Johnson et al. (1997), Vo and Pharm (2014), and Lucinda and Arvate (2005) has confirmed this positive relationship.

\subsection{Indicators of the Shadow Economy}

Several indicators of the shadow economy have been used in the literature such as labor force participation, money, and GDP. In our empirical study, we use GDP and money supply as two main indicators.

GDP: is an indicator whose relationship with the shadow economy does not have a consensus among economists. In addition, this relationship differs from one country to another. Some economists find that an increase in the level of GDP increased the demand for goods and services in the shadow economy (Tedds, 2005, Schneider \& Bajada, 2003, and Giles, 1999). Others see a negative relationship between official GDP and the shadow economy. They show that the increase in national income leads to an increase in economic development that is positively correlated with the level of taxpayer compliance. (Frey \& Weck-Hannemann, 1984, Schnieder \& Enste, 2000; Loayza, 1996; and Dell'Anno, 2003). For these economists a contraction in GDP increases 
unemployment, pushing the unemployed to work in the dark. In general, this indicator is used in several forms: GDP growth rate, GDP per capita or the ratio of current GDP to base year GDP, GDP per capita in logarithms. On the other hand, Schneider (2005) demonstrates the existence of a negative relationship for developing countries and countries in transition, and the existence of a positive relationship for developed countries between the two variables.

The monetary aggregate: is an important indicator for many economists. Indeed, agents in the shadow economy use cash in their transactions in order to avoid leaving traces and then escape paying taxes. However, an increase in the demand for real money in circulation is considered an indicator of the size of the shadow economy. Various variables are used in empirical work as a proxy for money in circulation to reflect the monetization rate in the economy: M1/M2 (e.g. Ene \& Stefanescou, 2011; Dell'Anno \& Solomon, 2008) M1/M3 (Dell'Anno et al., 2004; Dell'Anno et al., 2007), C/M3 (Giles, 1999), C/M2 (Schneider et al., 2010).

\section{Data and Estimation}

\subsection{Data Collection}

The data used are annual and cover the period from 1985 to 2016. They come from three main national organizations: The Office of the High Commissioner for Planning, the Ministry of the Economy and Finance and the Central Bank Bank-al Maghrib. Also, the World Bank's international database was used.

\subsection{Estimation of Model Parameters: Econometric Modelling}

The MIMIC model is trained with different combinations of the causes and indicators mentioned above. For the initial specification (7-1-2), the structural equation to be estimated, defining the relationship between the variable latent and its causes, includes seven causes of the shadow economy is given by:

$$
E S_{t}=\gamma_{1} X_{1 t}+\gamma_{2} X_{2 t}+\gamma_{3} X_{3 t}+\gamma_{4} X_{4 t}+\gamma_{5} X_{5 t}+\gamma_{6} X_{6 t}+\gamma_{7} X_{7 t}+\zeta
$$

With ES is the size of the shadow economy and $X_{i}$ are the different combinations from the previous causes of the shadow economy.

In this specification, we also have two measurement equations defining the relationship between the latent variable (shadow economy) and its indicators. The first equation, linking GDP per capita to the shadow economy, is given by:

$$
\operatorname{PIBperCap}_{t}=\lambda_{1} E S_{t}+\epsilon
$$

Where PIBperCap is the GDP per capita considered as the normalized variable, so its coefficient is set at -1 $\left(\lambda_{1}=-1\right)$. This coefficient can be set to 1 ou -1 depending on the assumed relationships between the latent variable and the indicator variables.

The second measurement equation that links the money supply C/M2 with the shadow economy is expressed as follows:

$$
C / M 2_{t}=\lambda_{2} E S_{t}+\epsilon
$$

Various specifications are estimated to obtain the best fit of the model by a maximum likelihood estimator using STATA 13. To examine the correct fit of the estimated model, we use several tests. The most popular test is the Mean Square Error of Approximation (RMSEA) test. For this test, the accepted models are considered to have a Pclose probability of less than 0.05 .

Table 1 summarizes the results obtained from four different specifications. In specification 1, we started with a general specification encompassing all the cause variables set out above. Then, we gradually removed the statistically insignificant variables in order to determine the most important variables that lead to the existence of the shadow economy in Morocco. Thus, in specification 2 we removed the inflation rate variable while in specification 3 the public expenditure variable is not considered.

Based on the results of the statistical tests obtained in these two specifications, we rejected the inflation rate and government expenditure and we obtained a 4th specification (5-1-2) which is considered to be the most appropriate adjustment of the model (see Figure 2). 
Table 1. The estimation results of the MIMIC model applied to the case of Morocco for the period 1985-2016

\begin{tabular}{|c|c|c|c|c|c|}
\hline \multirow{2}{*}{$\begin{array}{l}\text { Variables/ } \\
\text { specifications } \\
\text { Canes }\end{array}$} & \multicolumn{2}{|c|}{ Specification1 7-1-2 } & $\begin{array}{l}\text { Specification2 6-1-2 } \\
\text { Without inflation rate }\end{array}$ & $\begin{array}{l}\text { Specification3 6-1-2 } \\
\text { Without Public spending }\end{array}$ & $\begin{array}{l}\text { Specification4 } \\
5-1-2\end{array}$ \\
\hline & & & & & \\
\hline Unemployment rate & $0,36^{*}$ & $(4,99)$ & $0,33 *(4,79)$ & $0,34 * \quad(4,63)$ & $0,33 *(4,69)$ \\
\hline Agricole Added value & $-0,15$ & $(-1,55)$ & $-0,2 * * \quad(-2,3)$ & $-0,15 \quad(-1,54)$ & $-0,18^{* *} \quad(-2,07)$ \\
\hline Inflation rate & $-0,1$ & $(-1,12)$ & ------- & $-0,05 \quad(-0,54)$ & ------- \\
\hline Urbanization rate & $-1,3^{*}$ & $(-15,75)$ & $-1,23^{*} \quad(-20,67)$ & $-1,26^{*} \quad(-15,47)$ & $-1,23^{*} \quad(-20,24)$ \\
\hline Tax burden & 0,09 & $(1,19)$ & $0,12 * * * \quad(1,68)$ & $0,12 \quad(1,53)$ & $0,13 * * * \quad(1,77)$ \\
\hline Openness rate & $-0,07 * * *$ & $(-1,69)$ & $-0,11 * \quad(-3,09)$ & $-0,12^{*}(-3,16)$ & $-0,13^{*} \quad(-3,19)$ \\
\hline Public spending index & $-0,16$ & $(-1,56)$ & $-0,12 \quad(-1,21)$ & ------- & ------- \\
\hline \multicolumn{6}{|l|}{ Indicators } \\
\hline GDP per capita & \multicolumn{2}{|c|}{-1} & -1 & -1 & -1 \\
\hline Monetary aggregate & $0,7 *$ & $(12,49)$ & $0,7 * \quad(12,57)$ & $(12,49)$ & $(12,54)$ \\
\hline \multicolumn{6}{|l|}{ Statistic tests } \\
\hline Chi2 & \multicolumn{2}{|c|}{18,59} & 17,81 & 18,40 & 17,50 \\
\hline Pvalue & \multicolumn{2}{|c|}{0,01} & 0,007 & 0,005 & 0,004 \\
\hline RMSEA & \multicolumn{2}{|c|}{0,227} & 0,248 & 0,254 & 0,280 \\
\hline Pclose & \multicolumn{2}{|c|}{0,016} & 0,011 & 0,009 & 0,006 \\
\hline$C F I$ & \multicolumn{2}{|c|}{0,944} & 0,943 & 0,940 & 0,940 \\
\hline$T L I$ & \multicolumn{2}{|c|}{0,881} & 0,877 & 0,871 & 0,868 \\
\hline$S R M R$ & \multicolumn{2}{|c|}{0,036} & 0,034 & 0,04 & 0,038 \\
\hline$C D$ & & 1,0 & 1,0 & 1,0 & 1,0 \\
\hline
\end{tabular}

Note. Absolute values of $\mathrm{z}$ statistics are reported in brackets. The presence of single, double and triple asterisks $(*, * *, * * *)$ denotes significance levels of $1 \%, 5 \%$ and $10 \%$ respectively. Statistical tests reflect the quality of the model. In our case, these tests are acceptable. The CFI and TLI indices indicate a good fit of the model when they are close to 1. the SRMR indicates a good fit if it is less than 0.08 . For the $\mathrm{CD}$ determination coefficient, a perfect fit corresponds to $\mathrm{CD}=1$.

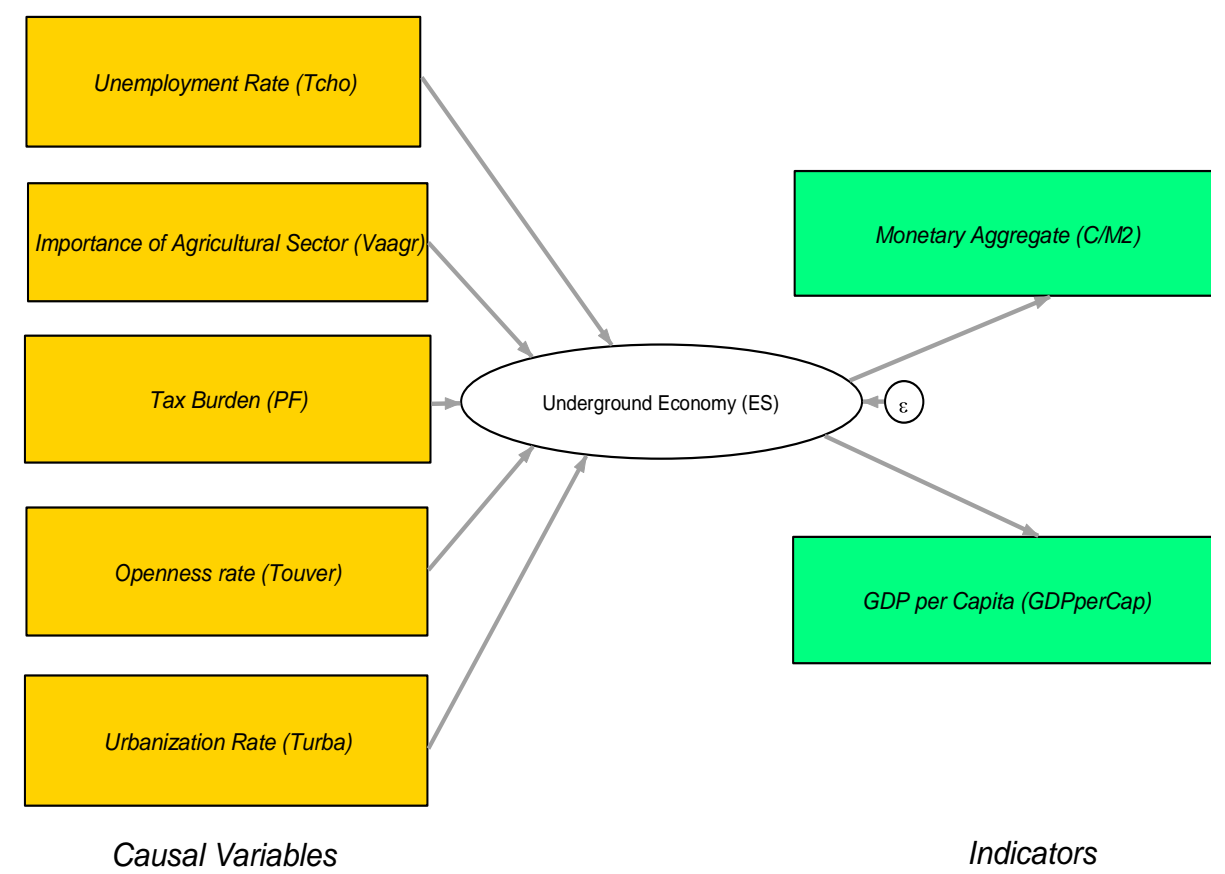

Figure 2. Specification 5-1-2 estimating the shadow economy

The study of correlations shows that the desired causal relationships exist between the latent variable and the explanatory variables considered statistically significant. Thus, the results of the MIMIC model indicate that the signs of the coefficients of the tax burden and the unemployment rate are positive as expected. These explanatory 
variables are significant at the $10 \%$ and $1 \%$ threshold respectively. This indicates that the effect of unemployment and tax pressure is leading to an increase in the shadow economy in Morocco.

The coefficient of agricultural added value is significant at $5 \%$, thus attesting that it is a cause of the shadow economy in Morocco. However, there is no positive correlation between this causal variable and the shadow economy. The correlation is actually negative, which could show that the links between these two variables are more complex. This result can be justified by the importance of agriculture in the Moroccan economy, a sector that essentially still remains in the informal sector and thus largely exempt from taxation.

The coefficients of the urbanization rate and the openness rate are significant at $1 \%$, attesting that these two variables are determining factors in Morocco's shadow economy. The signs of these coefficients are also negative, indicating that these two rates have opposite effects on the size of the shadow economy.

However, the estimated coefficients of the inflation rate and the public expenditure index are not statistically significant. They are both rejected. We can therefore argue that these two variables do not affect the size of the shadow economy in Morocco.

By substituting the estimated coefficients, we obtain the estimated equations below from the MIMIC model to quantify the shadow economy in Morocco.

\section{Measurement equations:}

$$
\begin{gathered}
\text { PIBperCap }_{t}=(-1) * E S_{t}-52,30 \\
C / M 2_{t}=0,70 * E S_{t}+77.8
\end{gathered}
$$

\section{Structure equation:}

$$
E S_{t}=0,33 * \text { Tcho }_{t}-0,18 * \text { Vaagr }_{t}+0,13 * P F_{t}-1,23 * \text { Turba }-0,13 * \text { Touver }
$$

From the resulting structural equation, we obtain annual indices of the shadow economy for the period 1985-2016. To convert these indices to shadow economy values as a percentage of GDP, a benchmarking and calibration procedure is required. In our case, we follow the procedure of Dell'Anno (2007), which is often used in empirical work. According to this procedure, the estimated shadow economy index, which has the same scale as the benchmark indicator (in this case GDP per capita), for a specific year $t$ is measured as a percentage of GDP in a base year $\mathrm{T}$ is linked to the index corresponding to changes in real GDP in the same base year by replacing the two indices in the measurement equation:

$$
\frac{P I B_{t}-P I B_{t-1}}{P I B_{T}}=\frac{\widetilde{E S}_{t}-\widetilde{E S}_{t-1}}{P I B_{T}}
$$

The shadow economy indices $\frac{\widetilde{E S}}{P I B_{T}}$ are obtained from the above structural equation.

Finally, Dell'Anno (2007) uses the following equation to estimate the size of the shadow economy as a percentage of PIB $\left(\frac{E S_{t}}{P I B_{t}}\right)$ :

$$
\frac{\widehat{E S}_{t}}{P I B_{t}}=\frac{\widetilde{E S}}{P I B_{T}} \frac{E S_{T}^{*}}{P I B_{T}} \frac{P I B_{T}}{\widetilde{E S}_{T}} \frac{P I B_{T}}{P I B_{t}}
$$

With: $\frac{\widetilde{E S}_{t}}{P I B_{T}}$ : the shadow economy index calculated by the structural equation.

$\frac{E S_{T}^{*}}{P I B_{T}}$ : the external estimate of the size of the shadow economy for Morocco in base year $\mathrm{T}$.

To apply this procedure to our case, an external estimate of the shadow economy in Morocco is required for one year in the period studied. This year is considered as base year T in the procedure. We choose 1999 as the base and calibration year because, for that year there was an external estimate of the size of the shadow economy as a percentage of GDP from Schneider et al. (2010) (the work most used in empirical work on benchmarking procedures). This estimate is equal to $36.4 \%$ of GDP, which corresponds to 148576.44 million MAD.

\section{Results and Discussion}

In the following, we present our results in estimating the shadow economy and tax evasion.

\subsection{Estimation of the Shadow Economy}

The results of our estimates reveal that the average annual size of the shadow economy in Morocco for the period 1985-2016 reaches $38.74 \%$ of GDP. Figure 3 illustrates the evolution of the size of the shadow economy as a percentage of GDP in Morocco from 1985 to 2016.

Figure 3 shows that the general evolution of the shadow economy in Morocco according to the MIMIC estimate 
showed a downward trend during the period 1985-2016. As a percentage of GDP, it decreased from $87.32 \%$ in 1985 to $17.89 \%$ in 2016 . However, a slight increase was recorded in 1997, when the shadow economy reached $40.17 \%$ instead of $39.45 \%$ a year earlier. These variations in the shadow economy are due to the net effects of the change in causal factors affecting the shadow economy according to our MIMIC model estimated for Morocco (Figure 4).

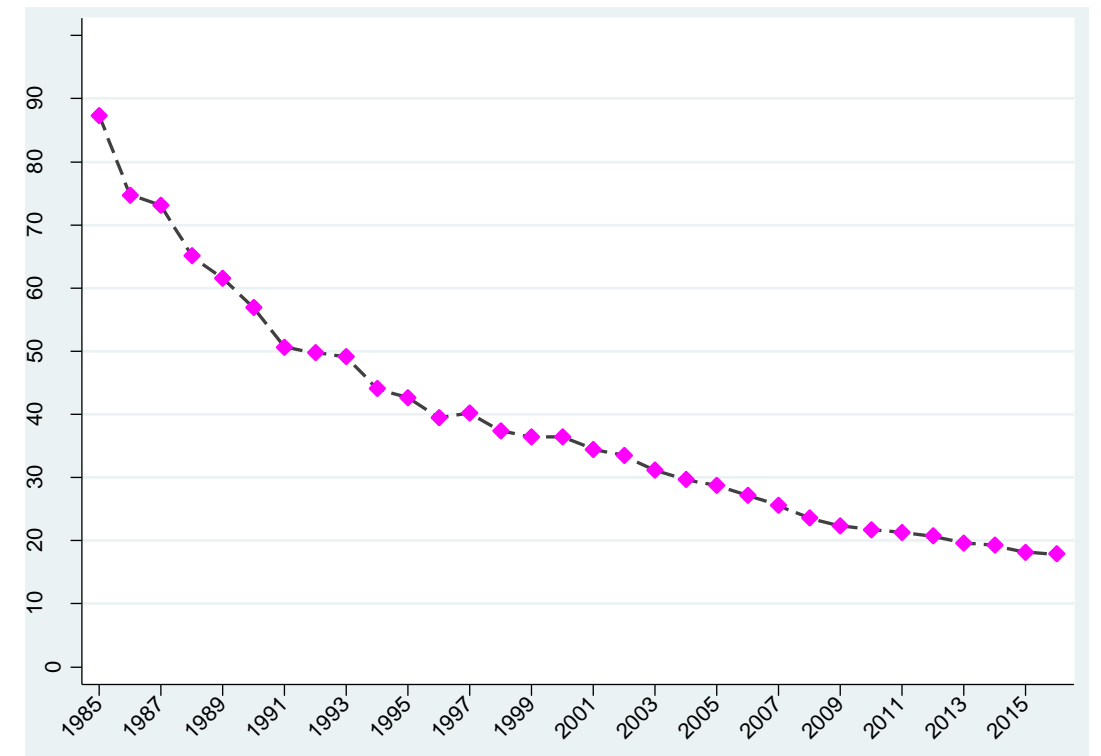

Figure 3. Evolution of the shadow economy in Morocco estimated by the MIMIC approach (\% of GDP)

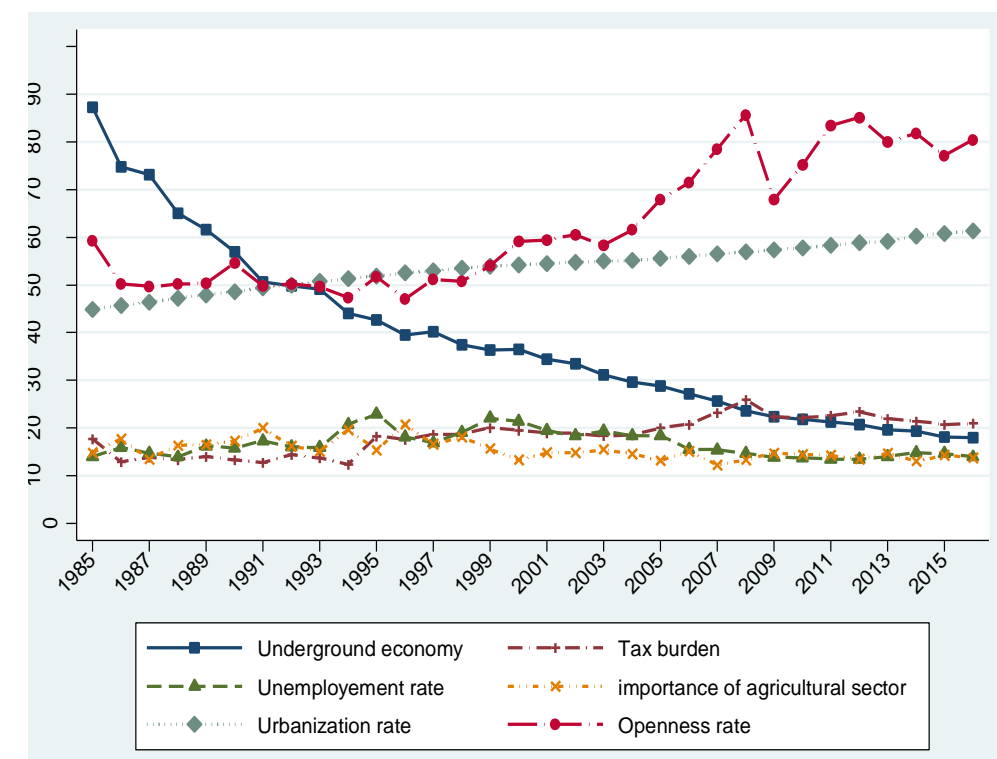

Figure 4. Trends in the shadow economy in Morocco and its causes using the MIMIC approach (in \%)

\subsection{Estimation of the Tax Evasion Size}

Several economist researchers such as Giles (1999) and Faal (2003) have conducted estimates of tax evasion in various countries based on their estimates of the shadow economy. They assume that the underground activities must be taxed in the same way as those of the official economy.

Following the methodology of these economists, we now attempt to estimate tax evasion by multiplying the tax burden by the estimated size of the shadow economy in Morocco by the MIMIC approach. Figures 5 and 6 present our estimates of the annual size of tax evasion in Morocco during the period 1985-2016 using the MIMIC approach, respectively in absolute terms and as a percentage of GDP. 


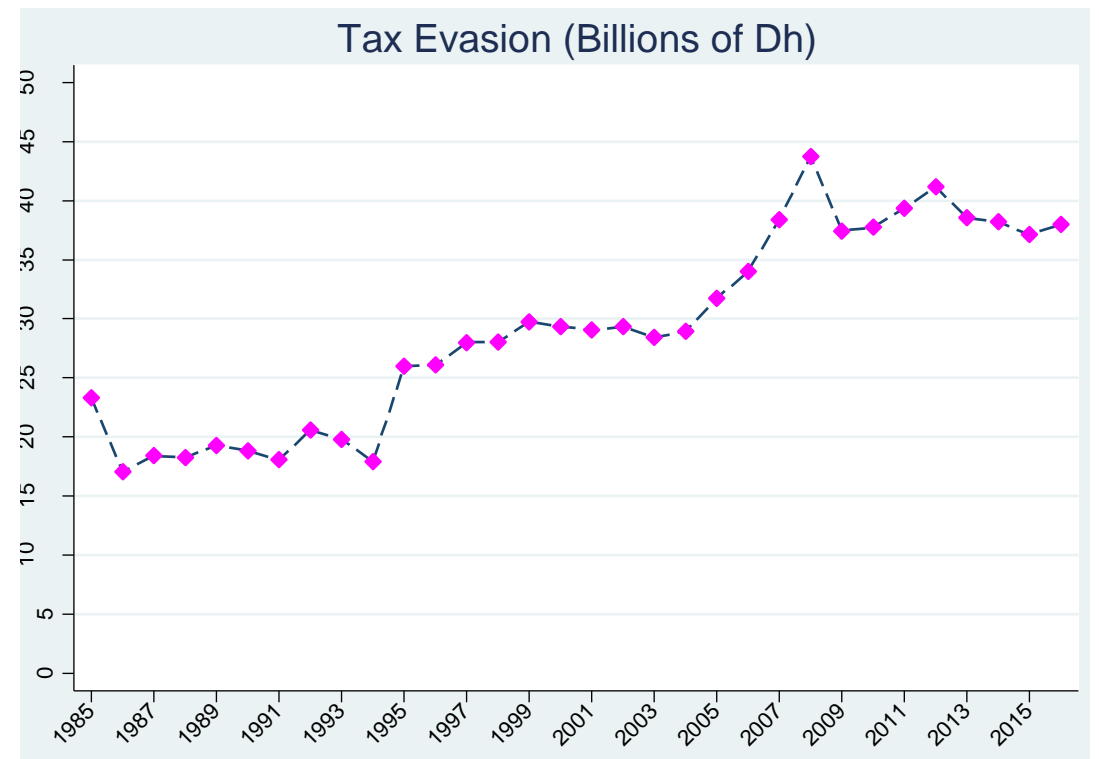

Figure 5. Trends of tax evasion in Morocco (Billions of MAD)

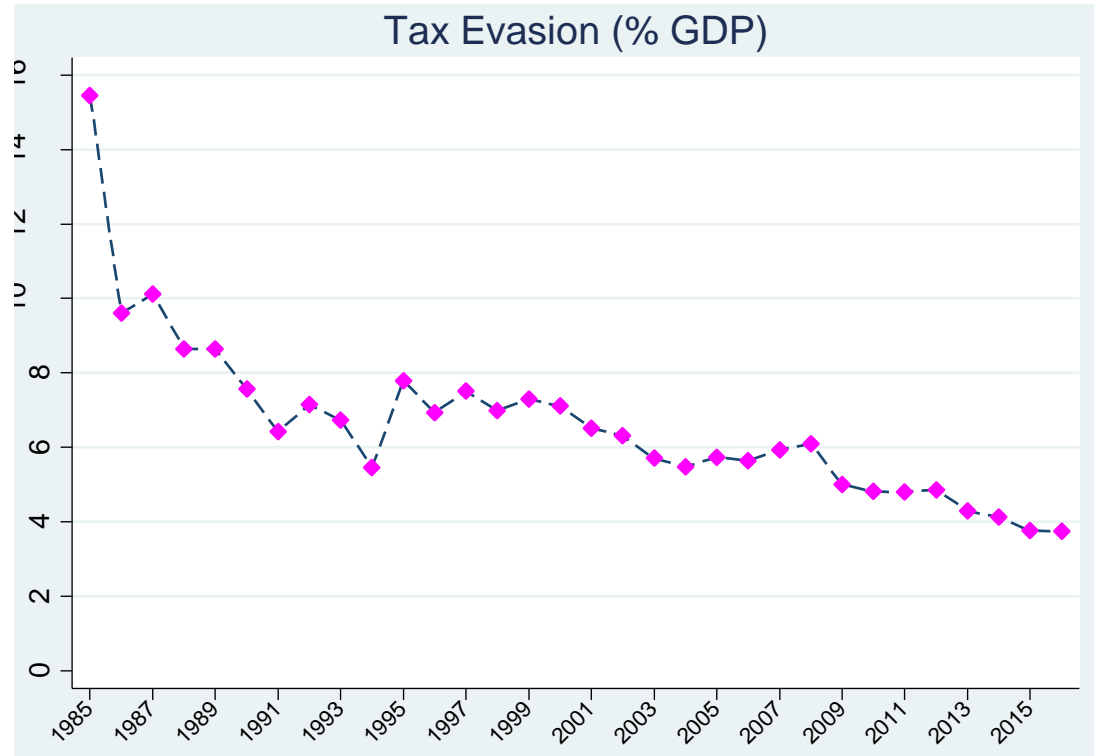

Figure 6. Trends of tax evasion in Morocco (\% of GDP)

The trend observed as shown in Figure 5 shows that tax evasion increases according to the MIMIC model, from 23.32 billion MAD in 1985 to 38 billion MAD in 2016, with an average annual growth rate of $1.6 \%$.

In 1986, tax evasion decreased to 17.03 billion MAD and remained slightly stable until 1994. Then, the period between 1995 and 2008 was characterized by an acceleration of exceptional magnitude to a peak of 43.75 billion in 2008 before falling back to 37.43 billion in 2009. In 2012, tax evasion experienced a second strong recovery. It fluctuates sharply upwards to 41.16 billion and then decelerates to 38.55 billion in 2013 . Then the rate of change in tax evasion was characterized by a significant stabilization until 2016.

As a percentage of GDP, tax evasion in Morocco has decreased, from $15.45 \%$ in 1985 to $3.74 \%$ in 2016 , an average of $6.19 \%$ over the same period. Year-on-year, the year 1986 saw a sharp decline of $5.8 \%$ compared with the previous year, reaching $10.1 \%$ of GDP in 1987. The downward trend in tax evasion continues, with an average of $7.2 \%$ between 1988 and 1994 compared with an annual average increase of $7.3 \%$ between 1995 and 2000. Second, the decline in tax evasion fell from $6.5 \%$ in 2001 to $3.7 \%$ in 2016, an annual average of $5.2 \%$ between the same period.

The main stylized trends in our tax evasion results are largely due to the process of variation in the various 
causal and indicator variables of the MIMIC model. In this sense, we note that the GDP per capita, the demand for money and the unemployment rate characterizing the evolution of the official economy are changing in terms of the spread of tax evasion behavior.

In this sense, the GDP per capita used in our study as an indicator of tax fraud, has been impacted by an unfavorable international and national context. Indeed, the recurrent exogenous shocks on the Moroccan economy since 2009 as a result of the international economic and financial crisis have contributed to a recession of national economic activity on average. This is illustrated by a decreasing growth rate of GDP per capita during this period. This rate decreases from an average of 5.2\% during the period 2000-2008 to an average of 3.6\% from 2009 to 2015. At the same time, tax evasion has developed in the opposite direction, increasing by an average of $4.5 \%$ in the first period compared to an average of $6.1 \%$ in the second period.

Another indicator of the tax evasion and the shadow economy concerns the monetary feature. Indeed, assuming that fraudsters engage in their fraud activities by concealing their transactions through the use of cash, the increase in tax evasion leads to a proportional increase in the demand for currency in circulation. As a result, the money supply in circulation specified by the central bank on the basis of official GDP figures becomes insufficient to meet demand. This would put high pressure on the inflation rate and interest rates. For example, the inflation rate in Morocco increased in 2008 by almost 1.7\% (from $2.01 \%$ in 2007 to $3.71 \%$ in 2008). This increase in inflation, as measured by the consumer price index, is largely due to soaring international oil prices and prices of basic foodstuffs and fresh produce, as well as private transport tariffs (Bank al Magrib, 2008). This coincides with the peak of tax evasion in 2008.

Concerning the causes introduced in our model, the increase in the number of unemployed in urban areas has a similar trend to tax evasion. In fact, over the period 1985-2000, the urban unemployment rate averaged $17.5 \%$, compared to an average of $15.7 \%$ between 2001 and 2016. At the same time, tax evasion shows the same trend in both periods with an average of $8.1 \%$ and $5.2 \%$ respectively.

Also, we note that the increasing peak of tax evasion in 2008 coincides with an exceptional increase in the tax burden and the rate of openness. Indeed, the tax burden amounted to $25.9 \%$ of GDP in 2008, an increase of 2.7 percentage points compared to 2007. This exceptional development is explained by the change in the structure of GDP in connection with the emergence of dynamic sectors (buildings and public works, post and telecommunications and financial and insurance activities, which have recorded significant increases in profits, generating significant tax revenues for the State (REF, 2017). However, missing revenues due to fraud have also increased visibly. This observation in particular, confirms the economic literature where any increase in the tax burden goes hand in hand with an increase in tax evasion.

In addition, the openness rate was marked by an upward trend between 1985 and 2016. This is largely explained by a progressive policy of liberalizing foreign trade. Thus, Morocco has signed various bilateral and multilateral free trade agreements, while pursuing a process of tariff dismantling in this context. This policy has been accompanied by the reform of customs taxation. For example, the maximum import duty on industrial products was reduced from $45 \%$ to $40 \%$ during the 2008 . In this year, the opening rate recorded a sharp increase compared to 2007 and 2009 (85.67\% in 2008 compared to $78.49 \%$ in 2007 and $67.92 \%$ in 2009). According to our estimates, the increase in the opening rate is consistent with the downward trend in tax evasion throughout the analysis period.

Concerning the agricultural sector, we have confirmed that agricultural added value is a cause of tax evasion with a negative effect despite the economic literature associating them with a positive relationship. Consequently, this apparent disconnection undoubtedly reflects the state of agricultural taxation in Morocco. Indeed, the agricultural sector benefited from a long total exemption from agricultural income until 2000 by royal decision. In 2000, this exemption was extended twice in a row by royal decision, once until the end of 2010 and once until 31 December 2014. Then, during the 2014 Finance Law, the legislator decided to integrate the agricultural sector into the Moroccan tax system in a progressive way.

As for the urbanization rate, Morocco has experienced an urbanization increase that has progressed over the years. According to the HCP (2014), this increase in the urban population is explained on one hand by natural population growth and on the other hand by the rural exodus, the creation of new urban centers and the extension of urban areas in cities. This urbanization, which is due to the concentration of the population in cities, is correlated with better access to public services, job creation following industrialization and capitalization and consequently, ensuring a tax revenue space that stimulates economic growth. In terms of evolution, the analysis shows that a negative relationship is clearly emerging between the urbanization rate and tax evasion. This relationship becomes clear if we compare the average evolution of the two variables. Indeed, the urbanization 
rate increased from an average of $49.8 \%$ between 1985 and 1999 to $57.2 \%$ between 2000 and 2016, while tax evasion decreased by 8.2\% of GDP between 1985 and 1999 compared to 5.3\% of GDP between 2000 and 2016.

In short, the analysis of these different indicators and causes of tax evasion leads us to conclude that several sectors and different types of taxes do not contribute to the tax effort to increase tax revenues. On the other hand, they represent targets of fraudulent maneuvers that result mainly in loss of tax revenue. This lack of tax resources caused by tax evasion creates a disparity between current and potential tax revenues as shown in Figure 7.

Consequently, the mobilization of the necessary resources and available resources to ensure the optimal exploitation of tax potential, through an effective fight against tax evasion, is an essential and fundamental step. This could lead to higher tax revenues and thus reduce the budget deficit.

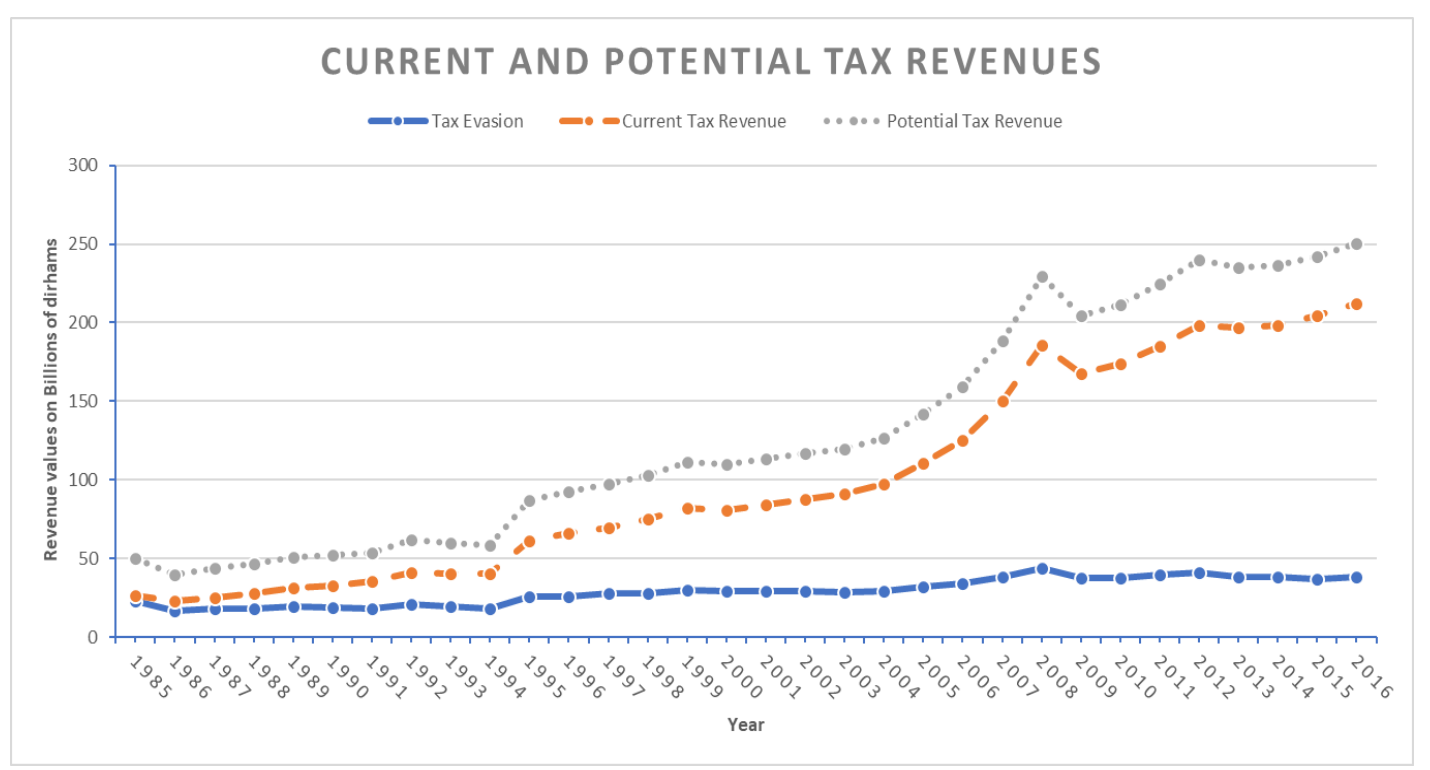

Figure 7. The size of tax evasion in Morocco compared to current tax revenues in billion dirhams

\section{Conclusion}

In this paper, we propose an attempt to quantitatively measure the extent of tax evasion based on an estimate of the size of the shadow economy. The approach used is based on the principle of the latent variable MIMIC. We are seeing a growing trend in terms of the absolute value (in million MAD) of tax evasion. Indeed, the proposed estimate leads to high amounts of tax evasion in Morocco during the period studied from 1985 to 2016 . On average, tax evasion in Morocco amounts to 57.35 billion MAD.

In addition, we were able to confirm that several determinants are behind this evolution of tax evasion in Morocco. These determinants are mainly the tax burden, the openness rate, the urbanization rate, the agricultural sector, and the unemployment rate.

This work is only a first attempt to estimate the extent of tax evasion in Morocco. There are undoubtedly several ways of developing this work. In fact, in this study we considered only some variables in our estimation model. It is therefore obvious to explore other variables.

Finally, this overestimated size of tax evasion represents only a part of the real tax evasion. In fact, in this study, the estimate was limited to tax evasion caused by the shadow sector while that of the organized sector remains unknown.

\section{References}

Aigner, D., Schneider, F., \& Ghosh, D. (1988). Me and my shadow: Estimating the size of the US hidden economy from time series data. In D. W. Barnett, E. Berndt, \& H. White (Eds.), Dynamic Econometric Modeling. Cambridge, UK: Cambridge University Press. https://doi.org/10.1017/CBO9780511664342

Alm, J., \& Yunus, M. (2009). Spatially and Persistence in U.S. Individual Income Tax Compliance. National Tax Journal, 62(1), 101-24. https://doi.org/10.17310/ntj.2009.1.05 
Angel-urdinola, D., Urdinola, D., \& Tanabe, K. (2012). Micro-Determinants of Informal Employment in The Middle East and North Africa Region, Social Protection and Labour. The World Bank, SP Discussion paper (1201), 48. https://openknowledge.worldbank.org/handle/10986/26828

Bank al-Maghrib. (2008). Rapport annuel présenté à sa Majesté, exercice 2008, Royaume du Maroc.

Boame, A. (2009). Individual Tax Compliance: A Time-Series Regression Using Canadian Data 1987-2003. Compliance Research and Measurement Section, Baseline Research Paper.

Bouchareb, M. (2005). La lutte contre la fraude fiscale au Maroc. Editions maghrébines.

Buehn, A. (2012). The shadow economy in german regions: An empirical assessment. German Economic Review, 13(3), 275-290. https://doi.org/10.1111/j.1468-0475.2011.00557.x

Buehn, A., \& Schneider, F. (2012). Shadow Economies Around the World: Novel Insights, Accepted Knowledge, and New Estimates. International Tax and Public Finance, 19, 139-171. https://doi.org/10.1007/s10797-011-9187-7

Buehn, A., \& Schneider, F. (2008). MIMIC Models, Cointegration and Error Correction: An Application to the French Shadow Economy. IZA Discussion Papers 3306, Institute for the Study of Labor (IZA).

Crane, S. E., \& Nourzad, F. (1986). Inflation and Tax Evasion: An Empirical Analysis. The Review of Economics and Statistics, 68(2), 217-223. https://doi.org/10.2307/1925500

Davoodi, H., \& Grigorian, D. (2007). Tax Potential vs. Tax Effort: A Cross-Country Analysis of Armenia's Stubbornly Low Tax Collection. IMF Work Paper /07/106.

Dell'Anno, R. (2003). Estimating the shadow economy in Italy: A structural equation approach. Aarhus, Denmark: Working Paper 2003-7, Department of Economics, University of Aarhus.

Dell'Anno, R. (2007). The shadow economy in Portugal: An analysis with the MIMIC approach. Journal of Applied Economics, 10, 253-277. https://doi.org/10.1080/15140326.2007.12040490

Dell'Anno, R., \& Solomon, O. H. (2008). Shadow Economy And Unemployment Rate In U.S.A. Is There A Structural Relationship? An Empirical Analysis. Applied Economics, Taylor Francis journals, 40(19), 2537-2555. https://doi.org/10.1080/00036840600970195

Dell'Anno, R., Gomez, M., \& Pardo, A. A. (2007). Shadow economy in three different Mediterranean countries: France, Spain and Greece. A MIMIC approach. Empirical Economics, 33, 51-84. https://doi.org/10.1007/s00181-006-0084-3

DEPF. (2017). Rapport Economique et Financier: Projet de Loi de Finances pour l'année budgétaire 2017. Ministère de l'Economie et des Finances, Royaume du Maroc.

Eiras, A. I. (2003). "Ethics, Corruption, and Economic Freedom", The Heritage Foundation Measuring the non-observed economy. Statistics Brief OECD, $n^{\circ} 5$.

Elgin, C., \& Oyvat, C. (2013). Lurking in the cities: Urbanization and the informal economy. Structural Change and Economic Dynamics, 27(C), 36-47. https://doi.org/10.1016/j.strueco.2013.06.003

Ene, C., \& Ştefănescu, A. (2011). Size and implication of underground economy in Romania- a MIMIC approach. Annales Universitatis Apulensis Series Oeconomica, 13(1), 77-86.

Essoulahi, M., \& Abbadi, A. (1980). La fraude fiscale dans les impôts directs au Maroc. Rabat: mémoire E.N.A.

Feige, E. (1979). How Big is the Irregular Economy? Challenge, 22, 5-13. https://doi.org/10.1080/05775132.1979.11470559

Feld, L. P., \& Schneider, F. (2010). Survey on the shadow economy and undeclared earnings in OECD countries. German Economic Review, 11(2), 109-49. https://doi.org/10.1111/j.1468-0475.2010.00509.x

Fishburn, G. (1981). Tax Evasion and Inflation. Australian Economic Papers, 20(37), 325-332. https://doi.org/10.1111/j.1467-8454.1981.tb00359.x

Frey, B. S., \& Pommerehne, W. (1984). The hidden economy: State and prospect for measurement. Review of Income and Wealth, 30(1), 1-23. https://doi.org/10.1111/j.1475-4991.1984.tb00474.x

Ghura, D. (1998). Tax Revenue in Sub-Saharan Africa: Effects of Economic Policies and Corruption. IMF Working Paper, No. 98/135, Washington DC. https://doi.org/10.5089/9781451855685.001

Giles, D. E. (1999). Modelling the Hidden Economy and the Tax-gap in New Zealand. Empirical Economics, 24, 621-640. https://doi.org/10.1007/s001810050076 
Giles, D. E., \& Tedds, L. M. (2002). Taxes and the Canadian underground economy. Canadian Tax Paper, 106. Canadian Tax Foundation, Toronto.

Goldberger, A. S. (1972). Structural Equation Methods in the Social Sciences. Amsterdam: North-Holland.

Guttmann, P. M. (1977). Subterranean Economy. Financial Analysis Journal. https://doi.org/10.2469/faj.v33.n6.26

Hassan, M., \& Schneider, F. (2016). Size and Development of the Shadow Economies of 157 Worldwide Countries: Updated and New Measures from 1999 to 2013. Journal of Global Economics, 4(3).

HCP. (2014). Note sur les premiers résultats du Recensement Général de la Population et de l'Habitat.

Internal revenue service. (1979). Estimates of Income Unreported on Individual Tax Reforms. Washington D.C.: Internal revenue service, U.S. Department of the Treasury.

Johnson, S., Kaufmann, D., \& Shleifer, A. (1997). The unofficial economy in transition. Brookings Papers on Economic Activity, Fall. https://doi.org/10.2307/2534688

Johnson, S., Kaufmann, D., \& Zoido-Lobatón, P. (1998). Corruption, public finances and the unofficial economy. Washington, D.C.: The World Bank, Discussion paper.

Kaufmann, D., \& Kaliberda, A. (1996). Integrating the unofficial economy into the dynamics of post socialist economies: A framework of analyses and evidence. In D. B. Kaminski (Ed.), Economic Transition in Russia and the New States of Eurasia. M.E. Sharpe.

Lackó, M. (1996). Hidden economy in East-European countries in international comparison. Luxemburg: Working paper, International Institute for Applied Systems Analysis (IIASA).

Loayza, N. V. (1996). The economics of the informal Sector: A simple model and some empirical evidence from Latin America. Carnegie-Rochester Conference Series on Public Policy, 45, 129-162. https://doi.org/10.1016/S0167-2231(96)00021-8

Lucinda, C. R., \& Arvate, P. (2005). A Study on the Shadow Economy and the Tax-Gap: The case of CPMF in Brazil. Public Choice Society.

Macafee, K. (1980). A Glimpse of the Hidden Economy in the National Accounts. Economic Trend, Central Statistical Office, London.

Macias, J. B., \& Cazzavillan, G. (2008). Modeling the Informal Economy in Mexico. A Structural Equation Approach. The Journal of Developing Areas, 44(1), 345-365. https://doi.org/10.1353/jda.0.0077

Medina, L., \& Schneider, F. (2017). Shadow Economies Around the World: New Results for 143 Countries Over 1996-2014. Discussion Paper, Department of Economics, University of Linz, Linz, Austria.

Naimi, M. (1982). Introduction à la question de la fraude fiscale dans le cas du Maroc. Diplôme du cycle de L'ISCAE.

O'Higgins, M. (1980). Measuring the Hidden Economy: A Review of Evidence and Methodologies. London: Outer Circle Policy Unit.

Richupan, S. (1984). Comment mesurer la fraude fiscale : brève description des principales techniques. Finances et Développement, 38-40.

Schneider, F. (2005). Shadow economies around the world: What do we really know? European Journal of Political Economy, 21(2), 598-642. https://doi.org/10.1016/j.ejpoleco.2004.10.002

Schneider, F. (2012). The shadow economy and work in the shadow: What do we (not) know. IZA Discussion Paper 6423.

Schneider, F., \& Bajada, C. (2003). The size and development of the shadow economies in the Asia-Pacific. Economics working papers, Department of Economics, University of Linz, Austria.

Schneider, F., \& Enste, D. (2000). Shadow Economies: Size, causes, and consequences. Journal of Economic Litterature, 38(1), 77-114. https://doi.org/10.1257/jel.38.1.77

Schneider, F., \& Enste, D. (2002). The Shadow Economy: Theoretical Approaches, Empirical Studies, and Political Implications. Cambridge (UK): Cambridge University Press.

Schneider, F., Buehn, A., \& Montenegro, C. E. (2010). New estimates for the shadow economies all over the world. International Economic Journal, 24(4), 443-461. https://doi.org/10.1080/10168737.2010.525974 
Stotsky, J., \& WoldeMariam, A. ( 1997). Tax Effort in Sub-Saharan Africa. IMF Working Paper, $N^{\circ}$ 97/107, Washington DC.

Tanzi, V. (1977). Inflation, lags in collection and the real value of the tax revenue. IMF Staff Papers 24, 154-167. https://doi.org/10.2307/3866540

Tanzi, V. (1999). Uses and abuses of estimates of the underground economy. Economic Journal, 109, 338-347. https://doi.org/10.1111/1468-0297.00437

Tedds, L. (2005). The Underground Economy in Canada. In D. C. B. Schneider (Ed.), Size, Causes and Consequences of the Underground Economy. Ashgate Publishing.

Torgler, B., \& Schneider, F. (2007). Shadow economy, tax morale, governance and institutional quality: A panel analysis. IZA Discussion Paper, No. 2563.

Vo, D. H., \& Pham, T. M. (2014). Any Link between Unofficial Economy and Official Economy? An Empirical Evidence from the ASEAN. International Journal of Economics and Finance, 6(11). https://doi.org/10.5539/ijef.v6n11p97

Vuletin, G. (2008). Measuring the Informal Economy in Latin America and the Caribbean. IMF Working Papers, $N^{\circ}$ 08/102. https://doi.org/10.5089/9781451869637.001

Wang, D. H., Lin, Y. J., \& Yu, T. H. (2006). A MIMIC approach to modeling the underground economy in Taiwan. Physica A 371, 536-542. https://doi.org/10.1016/j.physa.2006.03.060

Williams, C., \& Schneider, F. (2016). Measuring the Global Shadow Economy: The Prevalence in Formal Work and Labor. Cheltenham (UK): Edward Elgar Publishing Company. https://doi.org/10.4337/9781784717995

Zellner, A. (1970). Estimation of Regression Relationships Containing Unobservable Variables. International Economic Review, 11, 441-454. https://doi.org/10.2307/2525323

\section{Copyrights}

Copyright for this article is retained by the author(s), with first publication rights granted to the journal.

This is an open-access article distributed under the terms and conditions of the Creative Commons Attribution license (http://creativecommons.org/licenses/by/4.0/). 